\title{
Proposing a Capability Perspective on Digital Business Models
}

\author{
Rieke Bärenfänger \\ Institute of Information Management \\ University of St. Gallen \\ St. Gallen, Switzerland \\ rieke.baerenfaenger@unisg.ch
}

\author{
Boris Otto \\ Audi-Endowed Chair of Supply Net Order Management \\ Technical University of Dortmund \\ Dortmund, Germany \\ boris.otto@tu-dortmund.de
}

\begin{abstract}
Business models comprehensively describe the functioning of businesses in contemporary economic, technological, and societal environments. This paper focuses on the characteristics of digital business models from the perspective of capability research and develops a capability model for digital businesses. Following the design science research (DSR) methodology, multiple evaluation and design iterations were performed. Contributions to the design process came from IS/IT practice and the research base on business models and capabilities.
\end{abstract}

Keywords—business models; digitization; IS capabilities; dynamic capabilities

\section{Motivation}

Following the e-business model hype in the late 1990s, "digital business" appears to be the fashion of the 2000s. Whereas those who witnessed the e-business and ecommerce trend wonder whether " $\mathrm{d}$ is just the new e", implying the touted accelerating transformation of business models through digitization is more fad than fact, there is sufficient evidence in today's economy that the digitization trend brings along more profound implications than just the introduction of a new distribution channel as the e-commerce development did. In fact, digitization impacts entire business models; it not only questions incumbent ways of doing business, but also offers opportunities for new startups.

First examples of the impact of digitization on business models can be observed in a number of industries. A prominent characteristic of digitization is the integration of information technology into physical, formerly analog products [1], [2]. One example of such a "hybrid product" is a modern car with its numerous electronic components that allow monitoring the vehicle status including its surroundings (rain sensors, parking assist systems) and offer new ways of communication with the driver (bluetooth music placer connected to driver's MP3 player) and even with the outer world (GPS, remote service). Such hybrid products do not only offer additional functionality to customers, but also grant insights into usage patterns and technical product performance for car manufacturers.

A growing body of research attempts to categorize the changes business models currently undergo in view of digitization [3]-[5]. However, few have so far looked at the topic from an organizational and information systems (IS) capability perspective. Such a perspective, however, offers the potential to unveil the internal abilities that organizations should develop to optimally face digitization. It can thus be valuable for large established companies on their way to digital transformation as well as for digital entrepreneurs.

This paper therefore addresses the research question "Which organizational and data management capabilities do companies need for digital business models?". The goal of the research is to build a two-part capability model for the domain of digital business models. The main research question is addressed by answering two sub research questions:

Sub-RQ 1: Which organizational dynamic capabilities characterize digital business models?

Sub-RQ 2: Which requirements for data management capabilities follow from these capabilities?

The model serves two main objectives. Firstly, it helps understand the nature of digital business models. Secondly, it attempts to go beyond descriptive assessments of how digital business models are and develop first normative propositions on how the internal constituent elements of digital business models should look like.

The methodology chosen for this research follows the iterative design science research (DSR) approach, whose goal is to develop IT artifacts "to solve identified organizational problems" [6, p. 77]. DSR is considered appropriate for a practical design problem like the one faced by managers when pondering how to rearrange their available organizational resources or which new ones to acquire in view of digitization. The research paradigm strives for relevant results by close interaction with the practical research environment and for sufficient rigor by being thoroughly grounded in the relevant knowledge base [6]-[8].

The paper proceeds as follows. Section two introduces relevant work on digital business models and IS and organizational capabilities. Section three describes the design science research process. Section four develops the new dynamic capability model for digital business models and applies it to an exemplary digital business model. Section five presents findings regarding new data management capabilities in digital businesses. The final section 
summarizes the contributions to research and practice and provides an outlook on future research.

\section{BACKGROUND}

\section{A. Digital Business Models}

This paper uses the business model concept as a frame of reference. This research stream has been gaining increasing attention in general management and information systems research communities since its first appearance in the academic literature in the mid-1990s [9]. Literature reviews and meta-analyses [9]-[12] find that the business model has been heterogeneously defined and used. This paper adopts the definition from [10] who call the business model "a conceptual coherent framework that provides a holistic but abstract understanding of the underlying business logic of an organization" [10, p. 365].

Existing business model frameworks propose varying numbers of sub elements or dimensions to describe this business logic. Regardless of the final number, these elements usually answer the core questions that can be asked about the way a business works: Who is the customer, what is the main benefit of the product or service offering (the "value proposition"), and how does a company create and acquire this value. Value creation covers internal as well as collaborative processes and resources; financial value acquisition is expressed in the revenue model. In everyday speech, the term business model is often used when in fact only a certain sub element is meant. For example, the statement "they don't have a proper business model" often implies a company is not earning money (yet) and is thus lacking a sustainable revenue model. In this paper, however, we use the cited broader conceptualization, which refers to the entire "underlying business logic".

Digitization is an umbrella term summarizing various recent technological and societal developments brought along by the proliferation of ICT and the Internet. For example, it covers the increasing interconnectivity of people and devices via the Web (also called social media / Web 2.0 and Internet of Things, respectively), big data, mobile computing, and the confluence of physical and electronic products. A "digital business model" can thus be defined as a business model whose underlying business logic deliberately acknowledges the characteristics of digitization and takes advantage of them; both in interaction with customers and business partners, and in its internal operations.

Related research can be found under the terms "digital business strategy" (which was coined in particular in a special issue of the MISQ in June 2013, cf. [13]), "value architectures", or "digital services". Whereas early business model research in the IS domain used to focus on ecommerce and e-business applications only, emphasizing the role of the Internet as a new interaction and distribution channel, more recent contributions review the impact of digitization on value propositions and on value creation approaches.
Regarding value propositions in digital business models, sources like [4] stress the importance of combining content and experience for customers. Similarly, [5] analyze the nature of value in modern digital services in the context of serious games and find evidence for more "emergent" value propositions. In an article considered widely in the digital business research, [2] describe the structure of digital hybrid services as "layered" and "modular" and point to consequences in the way value is created. Turning to the implications for value creation in digital business models, several authors hold that the cocreation of value, i.e. closer collaboration with business partners and customers, is essential [3], [14]-[16].

Despite these contributions, there remains a need to understand the nature of digital business models in a more holistic way to highlight the special consequences for data management.

\section{B. Capabilities}

The research on organizational capabilities originates from the resource-based view of the firm (RBV), which tries to explain the sources of sustainable competitive advantage [17]. In line with the traditional RBV research, capabilities are considered here from an organizational perspective rather than from an individual perspective.

The capability research extends the RBV by finding that companies should not only possess resources that are valuable, rare, hard to imitate, and non-substitutable [17], [18], but also combine, develop and utilize these resources in a meaningful way as measured by company goals. These "capabilities" offer the advantage of being less imitable and transferable than most physical resources because they are embedded in organizational practices and individual skills linked to the unique history and culture of the firm [19]. The conceptualization of important organizational competencies and abilities as capabilities is well-established in various research domains, ranging from strategic management research over marketing, supply chain management, and IS research. To serve this paper's twofold goal of 1) understanding general organizational capabilities for digital business models and 2) analyzing the consequences for the area of IS capabilities, we draw on two particular streams of capability research.

On the one hand, for the first goal we turn to the "dynamic capabilities" research [20]-[23]. Dynamic capabilities are defined as "the firm's potential to systematically solve problems, formed by its propensity to sense opportunities and threats, to make timely and marketoriented decisions, and to change its resource base" [22, p. 271]. Similarly, [23] describe dynamic capabilities as "a set of capabilities [...] that help reconfigure existing operational capabilities into new ones that better match the environment" $[23$, p. 239]. Realizing relevant changes in the competitive environment and taking adequate business actions is inherent in the dynamic capability definition, which makes it well suited for a current topic like digitization. 
We use dynamic capabilities to more closely describe (digital) business models following the argumentation of [12]. They explain the relation between business strategy, dynamic capabilities and the business model by stating that "strategy entails devising dynamic capabilities able to respond to contingencies through the organization's business model" [12, p. 383]. They further argue that dynamic capabilities are implemented in the business model of an organization at a certain point in time. We therefore propose that in order to describe the nature of digital business models, it is justified to look at the dynamic capabilities that are considered important for digital businesses. In the capability model developed below, we thus include dynamic capabilities which are associated with businesses in the digital economy in research and practice and fit them into a business model framework.

On the other hand, for the second goal we consider capabilities in the IS research domain. An IS capability is defined as "a firm's ability to acquire, deploy, and leverage its IT-related resources in combination with other resources and capabilities in order to achieve business objectives" [24, p. 423]. In our case, the business objectives are given by the dynamic capabilities of digital business models. Most researchers regard IS capabilities as a multi-dimensional construct consisting of sub capabilities, including for example IT infrastructure, IT and data management, IT business partnerships, and IT infrastructure flexibility.

These general IS capabilities have continuously been found to be relevant in the IS research domain and can expected to remain important in light of digital business models. Attention should therefore turn to the details of these capabilities to find out how they need to change in the digitization context. As one sub area of the IS capabilities, data management deserves particular interest because digital business models center around intensified data use in various business areas. The leading practitioner organization DAMA, the Data Management Association, defines data management as "the business function of planning for, controlling and delivering data and information assets" [25, p. 4]. The discussion about "big data" and analytics [26] support the argument of data management's increasing importance for enabling digital business models. The second part of our capability model therefore turns to new data management capabilities.

\section{RESEARCH PROCESS}

The methodology chosen for this research is design science research (DSR), which aims at developing new and useful artifacts for research and practice. The most important characteristic of DSR is an iterative research and design process in close exchange with both the academic knowledge base and the targeted practitioner community. It typically undergoes the phases problem identification, design, design evaluation, and communication [6], [8]. A research environment that has proven useful for ensuring relevance in DSR is consortium research, which provides for close interaction between academic researchers and a number of partner companies [27]. Furthermore, frequent and early evaluation activities are recommended for DSR, whose inputs should be incorporated in subsequent design phases of the artifact [28]. Acknowledging these recommendations for DSR, this research followed an iterative process with three main phases as shown in Fig. 1.

In Phase 1, which took place from January to March 2014, we identified the problem and specified the design objectives of the capability model based on an initial literature review and interviews with practitioners. The research environment for the interviews and the subsequent evaluation activities was a "competence center" run at the authors' institute that currently comprises 18, mainly multinational research partner companies from a broad range of industries with a slight focus on manufacturing and process industries. Data managers from this group expressed a need for guidance in the redesign of their area of responsibility with regard to digital business models that could not be satisfied with their available knowledge. This shaped the DSR process' design objective to create a reference model of organizational and data management capabilities for digital business models that should be applicable to a broad range of industries.

Phase 2, the central phase of the DSR process, lasted from April to November 2014 and included multiple "design and evaluate" iterations as suggested by [28]. A summary of the first two evaluation phases is given in Table $I$.

Evaluation 1 was a focus group with eight data managers and took place at a workshop of the competence center on April 30, 2014. The goal of the focus group was to validate the design objectives and to brainstorm examples for digital business model scenarios and necessary capabilities in their organizations.

\begin{tabular}{|c|c|}
\hline $\begin{array}{l}\text { DSR } \\
\text { phase }\end{array}$ & $\begin{array}{c}1 \\
\text { Motivate } \& \text { Specify Objectives }\end{array}$ \\
\hline \multirow[t]{5}{*}{$\begin{array}{l}\text { Research } \\
\text { steps and } \\
\text { techniques }\end{array}$} & $\begin{array}{l}\text { January } 2014 \text { - March } 2014 \\
\text { - Literature research \& expert interviews: problem } \\
\text { identification and design objective specification }\end{array}$ \\
\hline & Build \& Evaluate \\
\hline & $\begin{array}{l}\text { April } 2014 \text { - November } 2014 \\
\text { - Evaluation } 1 \\
\text { - } 1^{\text {st }} \text { design phase } \\
\text { - Evaluation } 2 \\
\text { - Literature research and } 2^{\text {nd }} \text { design phase } \\
\text { - Evaluation } 3\end{array}$ \\
\hline & $\stackrel{3}{\text { Communicate }}$ \\
\hline & $\begin{array}{l}\text { November } 2014-\mathrm{Q} 12015 \\
\text { - Results communication in academic community: } \\
\text { academic paper } \\
\text { - Results communication in practitioner } \\
\text { community: presentation at consortium workshop }\end{array}$ \\
\hline
\end{tabular}

Figure 1. Research process 
The results were a collection of new value propositions and related value architectures, for example predictive maintenance in the case of a heavy equipment manufacturer or anticipatory shipping in case of a pharmaceuticals/biotech company. Based on this input, a first capability model was developed.

Evaluation 2 took place in late June of the same year and introduced the model to the wider audience of all participants of the next competence center workshop. The authors ensured all participants were familiar with the capability concept by answering questions in the plenary. The distinction between dynamic capabilities and ordinary data management capabilities was not made with the practitioners for the sake of simplicity of discussion.

The participants were asked to fill out a questionnaire that a) asked for a ranking of the different capabilities by importance for the different organizations, b) checked for ongoing activities in the different areas, and c) asked for additional capabilities that were not represented yet by several open-ended questions. Some exemplary remarks from the second evaluation round are reproduced below (the industry of the participant is included in brackets):

- "There is a need to bring the intelligence into our products" (engineering/control and automation).

- "Interaction with the customer in the digital market becomes more like a conversation instead of a static supply and demand process" (lighting).

- "I believe a new digital, virtual process design is required" (engineering/automotive supply).

- "We have increased analytics needs. Ensuring data quality is not enough - the information "extracted" from the data is key" (engineering/ telecommunication equipment).

TABLE I. EVALUATION STEPS 1 AND 2 IN THE RESEARCH PROCESS

\begin{tabular}{|l|l|l|}
\hline & $\begin{array}{l}\text { Evaluation 1: Focus } \\
\text { group discussion }\end{array}$ & $\begin{array}{l}\text { Evaluation 2: Focus group } \\
\text { discussion and survey }\end{array}$ \\
\hline Date & April 30, 2014 & June 26, 2014 \\
\hline $\begin{array}{l}\text { \# of } \\
\text { participants } \\
\text { (companies) }\end{array}$ & $8(7)$ & $37(14)$ \\
\hline $\begin{array}{l}\text { Industries } \\
\text { represented }\end{array}$ & $\begin{array}{l}\text { Engineering/automotive } \\
\text { supply, } \\
\text { Engineering/control and } \\
\text { automation, FMCG, } \\
\text { food processing, } \\
\text { pharmaceuticals / } \\
\text { biotech, software, } \\
\text { telecommunication } \\
\text { equipment }\end{array}$ & $\begin{array}{l}\text { Beverages, } \\
\text { engineering/automotive supply } \\
\text { (2x), engineering/control and } \\
\text { automation, } \\
\text { engineering/medical } \\
\text { technology, FMCG, lighting, } \\
\text { pharmaceuticals / biotech (3x), } \\
\text { software, telecommunication } \\
\text { equipment (2x), } \\
\text { telecommunication services }\end{array}$ \\
\hline $\begin{array}{l}\text { Evaluation } \\
\text { execution }\end{array}$ & $\begin{array}{l}\text { 2 hour focus group } \\
\text { discussion and } \\
\text { brainstorming on digital } \\
\text { business model scenarios }\end{array}$ & $\begin{array}{l}\text { 1.5 hour presentation of initial } \\
\text { capability model, Q\&A } \\
\text { session, survey for model } \\
\text { evaluation and additional items }\end{array}$ \\
\hline $\begin{array}{l}\text { Evaluation } \\
\text { outcomes }\end{array}$ & $\begin{array}{l}\text { Initial capability model } \\
\text { Revised capability model }\end{array}$ \\
\hline
\end{tabular}

The third evaluation will be covered in Section IV.B. Phase 3, communication of results, occurred both in the practitioner domain by presenting the revised model to the competence center group in a workshop in February 2015 and by this scientific paper for the research community.

\section{TOWARD A New DyNAMIC CAPABILITY MODEL FOR THE Digital Business}

\section{A. Development of the Dynamic Capability Model}

The DSR process combined with an additional literature research on relevant dynamic capabilities led to the development of a two-part capability model for digital business models. Its first part covers dynamic capabilities and the second part data management capabilities. Based on the view expressed by [12], the underlying general framework for the relation between data management capabilities, dynamic capabilities and digital business strategy as shown in Fig. 2. Digital business strategy is conceptualized here as the "fusion between IT strategy and business strategy", i.e. organizational strategy "formulated and executed by leveraging digital resources to create differential value" [13, p. 472].

To support the inputs from the DSR process, a literature review in leading IS and general management selected capabilities from the wider dynamic capability literature that could be associated with digital business models. The review used some interpretative discretion to include sources beyond the dynamic capability literature as long as the central construct in the respective research fit the dynamic capability definition mentioned in Section 2.2. Moreover, besides those capabilities that supported items mentioned by the practitioners in the evaluation cycles, sources needed to be sufficiently recent to be considered for inclusion in the model (publication date not older than 15 years), and should have a focus on digitization. The resulting model is shown in Fig. 3. As it was not the goal of this paper to develop yet another "n-element" framework for business models, but rather to focus on their internal configuration with regard to digitization, we borrow from the simple frameworks from [29] and [10] and just distinguish the three elements value proposition, value creation, and value appropriation.

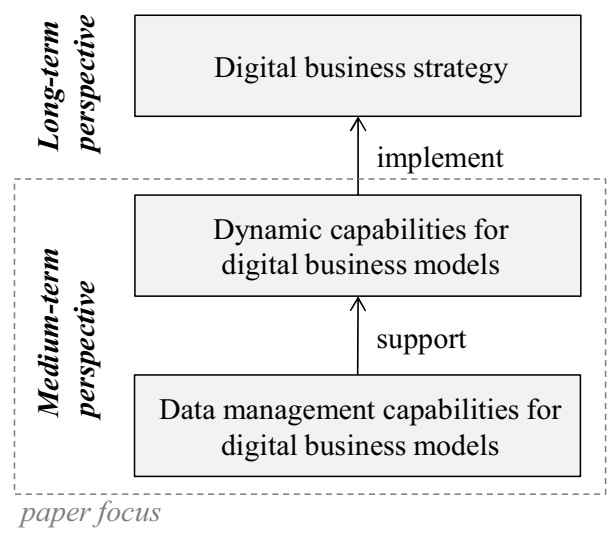

Figure 2. General reference model 


\begin{tabular}{|c|c|c|}
\hline \multicolumn{3}{|c|}{ Dynamic capabilities for Digital Business Models } \\
\hline Value proposition & Value creation & Value appropriation \\
\hline $\begin{array}{l}\text { - Hybrid modular } \\
\text { product \& service } \\
\text { development } \\
\text { - Market } \\
\text { capitalizing } \\
\text { agility }\end{array}$ & $\begin{array}{l}\text { - Business analytics \& } \\
\text { evidence-based decision } \\
\text { making } \\
\text { - Operational adjustment } \\
\text { agility } \\
\text { - Process digitization } \\
\text { (advanced automation \& } \\
\text { virtualization) } \\
\text { - Multi-channel ecosystem } \\
\text { connectivity } \\
\text { - Ecosystem control } \\
\text { - Knowledge management } \\
\text { and data-oriented } \\
\text { organizational design }\end{array}$ & $\begin{array}{l}\text { - Revenue model } \\
\text { execution for } \\
\text { hybrid modular } \\
\text { products \& } \\
\text { services } \\
\text { - Cost optimization } \\
\text { and process \& } \\
\text { resource } \\
\text { efficiency }\end{array}$ \\
\hline
\end{tabular}

Figure 3. Dynamic capability model for digital business models

In contrast to most empirical work available on dynamic capabilities, our model does not focus on a single dynamic capability, but argues that a realistic digital business model features multiple dynamic capabilities. They should thus be considered jointly rather than exclusively. This is not to say that every company needs to develop all these capabilities to the same extent, but we suggest that companies attempting to embrace digitization can benefit from being aware of all of these capabilities and from prioritizing them according to their digital business strategy.

The following table (Table II) displays explanations of the ten dynamic capabilities with their origin in the DSR steps and supporting literature. The column "origin in DSR steps" shows at which point in time of the "design and evaluate" DSR phase the item was added - either after the original focus group or after the second evaluation step based on additional practitioner feedback and the complementary literature research.

TABLE II. OVERVIEW OF DYNAMIC CAPABILITIES

\begin{tabular}{|l|l|l|}
\hline Dynamic capability & $\begin{array}{l}\text { Origin in } \\
\text { DSR } \\
\text { step }\end{array}$ & $\begin{array}{l}\text { Supporting } \\
\text { literature }\end{array}$ \\
\hline Value proposition & Eval. 1 & $\begin{array}{l}{[1],[2],} \\
{[30],[31]}\end{array}$ \\
\hline $\begin{array}{l}\text { (1) Hybrid modular product \& service } \\
\text { development } \\
\text { fapability to offer value propositions } \\
\text { products ("s) a combinitization") and (b) an } \\
\text { integration of modern ICT into physical } \\
\text { products ("hybrid products"). This may lead to } \\
\text { a modular product structure. }\end{array}$ & & \\
\hline $\begin{array}{l}\text { (2) Market capitalizing agility } \\
\text { Capability to have an entrepreneurial mindset } \\
\text { within the organization that allows to quickly } \\
\text { spot trends in the market and to develop } \\
\text { innovative products. }\end{array}$ & Eval. 1 & [32]-[34] \\
\hline Value creation & \\
\hline (3) Business analytics \& evidence-based & Eval. 1 & [30], [35]- \\
\hline
\end{tabular}

\begin{tabular}{|c|c|c|}
\hline $\begin{array}{l}\text { decision making } \\
\text { Capability of well-informed decision making } \\
\text { and problem solving based on sufficient data } \\
\text { (analysis) base. This envisions enabling all } \\
\text { organizational members to decide and act } \\
\text { based on timely and sufficient information. }\end{array}$ & & {$[38]$} \\
\hline $\begin{array}{l}\text { (4) Operational adjustment agility } \\
\text { Capability of organizational process flexibility } \\
\text { and flexible and fast implementation of } \\
\text { operational changes (e.g. supply chain agility). }\end{array}$ & Eval. 2 & {$[32],[39]$} \\
\hline $\begin{array}{l}\text { (5) Process digitization (advanced } \\
\text { automation \& virtualization) } \\
\text { Capability to automate business processes to } \\
\text { the greatest possible extent throughout the } \\
\text { organization, combined with process } \\
\text { digitization or virtualization to ensure process } \\
\text { transparency. }\end{array}$ & Eval. 1 & $\begin{array}{l}{[37],[40]-} \\
{[42]}\end{array}$ \\
\hline $\begin{array}{l}\text { (6) Multi-channel ecosystem connectivity } \\
\text { Capability to be continuously connected to all } \\
\text { partners of the corporate ecosystem - also } \\
\text { beyond the traditional supply chain- } \\
\text { including customers (and consumers), } \\
\text { business partners such as suppliers or co- } \\
\text { creators of value, and public stakeholders. } \\
\text { This connectivity covers the capability for in- } \\
\text { and outbound communication via multiple } \\
\text { channels as well as a superior understanding } \\
\text { of the ecosystem partners based on all relevant } \\
\text { internal and external and information sources. }\end{array}$ & Eval. 1 & $\begin{array}{l}{[15],[42]-} \\
{[45]}\end{array}$ \\
\hline $\begin{array}{l}\text { (7) Ecosystem control } \\
\text { Capability to transfer ecosystem knowledge } \\
\text { and connectivity into actual control over } \\
\text { suppliers and other business partners } \\
\text { according to business goals. }\end{array}$ & Eval. 2 & {$[31]$} \\
\hline $\begin{array}{l}\text { (8) Knowledge management and data- } \\
\text { oriented organizational design } \\
\text { Capability to ensure sufficient capturing, } \\
\text { exchange, and development of employee } \\
\text { knowledge throughout the organization. } \\
\text { Furthermore, the internal organizational } \\
\text { structure should reflect the importance of data } \\
\text { for the organization, e.g. by adequate roles } \\
\text { ("chief digital officer") and team structures. }\end{array}$ & Eval. 2 & $\begin{array}{l}\text { [34], [38], } \\
{[43]}\end{array}$ \\
\hline \multicolumn{3}{|l|}{ Value appropriation } \\
\hline $\begin{array}{l}\text { (9) Revenue model execution for hybrid } \\
\text { modular products \& services } \\
\text { Capability to identify and sustainably operate } \\
\text { pricing schemes and revenue models for the } \\
\text { new hybrid modular product portfolio. }\end{array}$ & Eval. 2 & {$[46],[47]$} \\
\hline $\begin{array}{l}\text { (10) Cost optimization and process \& } \\
\text { resource efficiency } \\
\text { Capability to operate internal resources and } \\
\text { ordinary capabilities in a cost-efficient manner } \\
\text { with adequate flexibility to rapidly scale up, } \\
\text { down, and/or out depending on competitive } \\
\text { demands. }\end{array}$ & Eval. 2 & {$[43],[48]$} \\
\hline
\end{tabular}

\section{B. Theoretical Application and Evaluation of the Dynamic Capability Model}

DSR recommends testing an artifact prototype in a suitable practical context. In the research at hand, this was covered in research step Evaluation 3. We evaluated the 
prototype by applying it to an existing digital business model to see whether the dynamic capabilities defined in the model fit to what can be observed in a real-life business.

We decided to choose Nest, an electronic, programmable, and self-learning thermostat as exemplary digital business model because it has been recognized as such in previous research. Studies like [13] about digital business strategy and [3] or [30] about digital business models already used Nest as example. The judgment was based on publicly available information such as Nest's homepage and press releases. Therefore, not all categories could be assessed with certainty. Table III presents the assessment of Nest's business model with respect to the ten dynamic capabilities.

TABLE III. APPLICATION OF DYNAMIC CAPABILITY MODEL TO THE BUSINESS MODEL OF NEST

\section{(1) Hybrid modular product \& service development \\ Applicable: The thermostat includes "physical product" / hardware and software components. Moreover, it can be combined with other products such as Dropcam or Nest Protect, which is in line with the "modular product platform" idea.}

\section{(2) Market capitalizing agility}

Applicable: The business model takes up and capitalizes on current societal trends like mobility and energy-saving behavior while recognizing design best practices like ease-of-use and visual appeal.

\section{(3) Business analytics \& evidence-based decision making}

At least partly applicable: Presumably, Nest is able to perform business analytics activities, both internally and as a service offered to customers. The thermostats are connected to personal online customer accounts, which is a necessary prerequisite for analyses of consumption patterns of the customer base and for the thermostat's self-learning ability in homes. The exact internal analytics capabilities cannot be judged.

(4) Operational adjustment agility

Cannot be assessed with public data.

(5) Process digitization (advanced automation \& virtualization) At least partly applicable: Again, the thermostat's software components and its connection to the internet enable automated functioning including a self-learning ability of customer consumption habits and a virtual activity tracking. However, public data does not allow for evaluation of the degree of automation and digitization of internal processes (e.g., manufacturing).

\section{(6) Multi-channel connectivity to ecosystem}

Applicable: Nest communicates with its customers by multiple channels, both offline and online. Its software runs with the two dominant mobile ecosystems, Android and iOS. Nest publishes the application programming interface (API), allowing other solutions to be built around its core service. Nest states that some energy providers ship the thermostat for free when the customer signs up for certain plans. Since June 2014, Nest (that is, its now-parent Google) also collaborates with other technology companies like Samsung and ARM to develop a new standard networking protocol for IoT communication $^{1}$.

\section{(7) Ecosystem control}

At least partly applicable: Indications of ecosystem control activities are Nest's collaborations with energy companies in Canada, the US and the UK to offer bundles of learning thermostats and electricity contracts, thereby creating pressure on other incumbent market players and the

\footnotetext{
1 See $\quad$ http://uk.reuters.com/article/2014/07/15/uk-google-nest-
} idUKKBNOFK0JV20140715

\section{utilities.}

(8) Knowledge management and data-oriented organizational design Cannot be assessed with public data.

(9) Revenue model execution for hybrid modular products \& services At least partly applicable: Nest's primary revenue source is classical product sales. With an easy-to-use monthly energy savings calculator on the web, Nest allows its customers to calculate how much they can save after purchase to lower customers' purchasing wariness. Whereas the true profitability of the revenue model can currently not be assessed, the $\$ 3.2$ billion purchase by Google indicates the company believes in Nest's financial value potential.

(10) Cost optimization and process $\&$ resource efficiency

Cannot be assessed with public data.

With seven of ten capabilities assessed positively based on the available data, we conclude that the model fits reasonably well to an existing real-world digital business. It also seems sufficiently comprehensive by capturing the prominent aspects of Nest's business model. In future research, the model could be applied to other digital business models with using other in-depth research settings, for example case study research.

\section{DATA MANAGEMENT CAPABILITIES}

We now turn to the second research question of this study, the consequences of these dynamic capabilities of digital business models for data management capabilities (see Fig. 4). As mentioned above, data management capabilities support the realization of dynamic capabilities. Multiple of the dynamic capabilities directly depend on proper data management for their successful execution, for example capabilities No. 1, 3, 5, 6, 7, and 8. These dynamic capabilities require adequate integration, analysis, and provisioning of data in the right quality, at the right time, and to the right stakeholders. It is therefore reasonable to assume that digital business models also pose new requirements to data management, which was supported by the evidence collected in the DSR process. The remainder of this section summarizes these main new data management capabilities.

\begin{tabular}{|c|c|c|}
\hline Data management & $\begin{array}{l}\text { Data understanding and } \\
\text { transformation }\end{array}$ & $\begin{array}{l}\text { Data delivery and } \\
\text { exploitation }\end{array}$ \\
\hline $\begin{array}{l}\text { - Data collection and } \\
\text { integration of } \\
\text { internal \& external } \\
\text { sources } \\
\text { - DQM and MDM } \\
\text { across systems and } \\
\text { ecosystems } \\
\text { - Governance } \\
\text { modeling and } \\
\text { architecture design } \\
\text { for external and } \\
\text { shared data }\end{array}$ & $\begin{array}{l}\text { - Ad-hoc, predictive, } \\
\text { and prescriptive } \\
\text { analytics processing } \\
\text { - New databases and BI } \\
\text { tools integration } \\
\text { - Analytics ability: } \\
\text { relevant data } \\
\text { recognition and } \\
\text { extraction }\end{array}$ & $\begin{array}{l}\text { - Information } \\
\text { service } \\
\text { visualization } \\
\text { - Self-service BI } \\
\text { provisioning } \\
\text { - } \begin{array}{l}\text { Digital initiative } \\
\text { ownership } \\
\text { definition }\end{array}\end{array}$ \\
\hline
\end{tabular}

Figure 4. Data management capabilities for digital business models 
Data collection and integration of internal \& external sources. The capability to effectively integrate data from different internal and external sources in various formats. This includes both better integration of so-far underutilized internal data sources (such as the integration of production data with data residing in BI, ERP, and CRM systems or with unstructured data like text files), and the integration of external sources (e.g. from social media and other web data sources, or from external data providers).

DQM and MDM across systems and ecosystems. The capability to provide trustworthy master data management (MDM) of the central business entities across systems, if necessary also in collaboration with partners in the ecosystem. Data quality management (DQM) and adequate data privacy and security management also need to be in place for core data objects.

Governance modeling and architecture design for external and shared data. The capability to design and operate topical data governance concepts that account for more diverse data sources as well as internal and external data stakeholders. It includes the capability to design an adequate information and system architecture in view of growing deployment method and tool diversity (e.g. cloud services or open source software).

Ad-hoc, predictive, and prescriptive analytics processing. The capability of sophisticated data analytics modeling and execution, supported by adequate software and hardware for digital decision-support and problem-solving scenarios. Whereas classical business intelligence mainly focused on reporting of past data, digital business models flourish with sophisticated data analyses like prescriptive modeling and simulation, which also look into the future. Furthermore, modern technology allows for support of "realtime" or "ad-hoc" scenarios such as delivery route optimization in real-time for a logistics provider.

New databases and BI tools integration. The capability to evaluate, integrate, and operate new databases and tools (especially for analytics and speed and scalability requirements) within the current IT architecture. Maybe even more than the other data management capabilities, this one is subject to dynamic capability No. 10 (cost optimization and process \& resource efficiency) and therefore needs to consider concepts for cost-effective and flexible infrastructure operations such as cloud computing and Software-as-a-Service (SaaS).

Analytics ability: relevant data recognition and extraction. The capability to have the skills available, which are necessary to extract relevant data out of the "big data lake" and to prepare them for business decision making and problem solving. In this context, the "data scientist" [49], [50] is frequently mentioned as a new indispensable employee profile and refers to a person who is able to perform complex data analyses while simultaneously possessing profound understanding of business matters. Although it has yet to be seen whether these skills really need to be present within one person or can instead be built up in an entire department, or whether analytics tools will become sufficiently user-friendly to render special statistical knowledge redundant - many believe that efforts to build up adequate IT expertise will need to intensify in the short- to medium term.

Information service visualization. The capability to deliver data analysis results in appropriate formats (i.e., easily comprehensible) across adequate platforms such as laptops, mobile devices, and web portals.

Self-service BI provisioning. The capability to empower business users throughout the organization to perform desired analyses on their own.

Digital initiative ownership definition. The capability to assign clear roles and responsibilities for digital initiatives within the organization, bridging functional boundaries.

\section{CONCLUSION}

This research addresses the question which capabilities companies need for operating successful digital business models by proposing a two-part capability model featuring ten organizational dynamic capabilities and nine data management capabilities. The model is the outcome of a design science research process, which ensured that the latest concerns and expectations regarding digitization of IS/IT managers in leading multinational companies from multiple industries are represented in the two parts of the model. A theoretical application to the digital business model of the intelligent home thermostat Nest showed the model's practical suitability. This paper therefore answers essential questions about the nature of digital business models: what is the value proposition of digital business models and how should value be created and acquired.

The paper contributes to both research and practice. For research, the paper adds to the growing knowledge base on business models in the context of a contemporary phenomenon like digitization. Practitioners may benefit from this research by gaining an overview of necessary organizational and data management capabilities that are relevant to prepare for the demands of the digital economy. More concretely, the capability model may serve managers with the mandate to establish a new "digital organization" with first indications as to which digital initiatives may be worthwhile to pursue (e.g., initiatives that support any of the dynamic capabilities). The data management capabilities can serve as a checklist for people in charge of data management or information management by pointing out what to consider when supporting digital initiatives from a data management perspective.

As any research, this one is not without limitations. Firstly, despite multiple design and evaluate iterations and the thorough literature review, we cannot ensure that the model is complete because our group of practitioners and the authors may not have found all relevant capabilities for digital business models. Secondly, owing to the qualitative research method, we cannot claim with certainty that all 
mentioned capabilities, both the organizational and data management ones, are equally important, let alone statistically significant in explaining digital business model success. However, it would be a valid field for future research to analyze the relative importance of the different capabilities more accurately. Finally, we encourage application of the model to more real-life digital businesses in order further validate the model and describe the individual capabilities in greater detail.

\section{REFERENCES}

[1] J. Björkdahl, "Technology cross-fertilization and the business model: The case of integrating ICTs in mechanical engineering products," Res. Policy, vol. 38, no. 9, pp. 14681477, 2009.

[2] Y. Yoo, O. Henfridsson, and K. Lyytinen, "Research Commentary-The New Organizing Logic of Digital Innovation: An Agenda for Information Systems Research," Inf. Syst. Res., vol. 21, no. 4, pp. 724-735, 2010.

[3] S. Turber and C. Smiela, "A Business Model Type for the Internet of Things," in Proceedings of the European Conference on Information Systems (ECIS) 2014, 2014, pp. $1-10$.

[4] P. Weill and S. L. Woerner, "Optimizing your Digital Business Model," MIT Sloan Manag. Rev., vol. 54, no. 3, pp. 71-78, 2013.

[5] K. Antonopoulou, J. Nandhakumar, and N. Panourgias, "Value Proposition for Digital Technology Innovations of Uncertain Market Potential," in Proceedings of the European Conference on Information Systems (ECIS) 2014, 2014, pp. $1-16$.

[6] A. R. Hevner, S. T. March, J. Park, and S. Ram, "Design Science in Information Systems Research," MIS Q., vol. 28, no. 1, pp. 75-105, 2004.

[7] S. Gregor and A. R. Hevner, "Positioning and Presenting Design Science Research for Maximum Impact," MIS Q., vol. 37, no. 2, pp. 337-355, 2013.

[8] K. Peffers, T. Tuunanen, M. A. Rothenberger, and S. Chatterjee, "A Design Science Research Methodology for Information Systems Research,” J. Manag. Inf. Syst., vol. 24, no. 3, pp. 45-77, 2008.

[9] C. Zott, R. Amit, and L. Massa, "The Business Model: Recent Developments and Future Research," J. Manage., vol. 37, no. 4, pp. 1019-1042, May 2011.

[10] M. M. Al-Debei and D. Avison, "Developing a unified framework of the business model concept," Eur. J. Inf. Syst., vol. 19, no. 3, pp. 359-376, May 2010.

[11] T. Burkhart, D. Werth, J. Krumeich, and P. Loos, “Analyzing the Business Model Concept - A Comprehensive Classification of Literature," in Proceedings of the 32nd International Conference on Information Systems (ICIS) 2011. Shanghai, China, 2011, pp. 1-19.

[12] C. M. DaSilva and P. Trkman, "Business Model: What It Is and What It Is Not," Long Range Plann., vol. 47, no. 6, pp. 379-389, 2013.

[13] A. S. Bharadwaj, O. A. El Sawy, and P. A. Pavlou, "Digital Business Strategy: Toward a Next Generation of Insights," MIS Q., vol. 37, no. 2, pp. 471-482, 2013.
[14] R. F. Lusch and S. Nambisan, "Service Innovation: A Service-Dominant Logic Perspective," MIS Q., vol. 39, no. 1, pp. 155-175, 2015.

[15] P. Keen and R. Williams, "Value Architectures for Digital Business: Beyond the Business Model," MIS Q., vol. 37, no. 2, pp. 643-648, 2013.

[16] E. Brousseau and T. Penard, "The Economics of Digital Business Models: A Framework for Analyzing the Economics of Platforms," Rev. Netw. Econ., vol. 6, no. 2, pp. 81-114, 2007.

[17] J. Barney, "Firm Resources and Sustained Competitive Advantage," J. Manage., vol. 17, no. 1, pp. 99-120, 1991.

[18] F. J. Mata, W. L. Fuerst, and J. B. Barney, "Information Technology and Sustained Competitive Advantage: A Resource-Based Analysis," MIS Q., vol. 19, no. 4, pp. 487506, 1995.

[19] A. S. Bharadwaj, V. Sambamurthy, and R. W. Zmud, "IT Capabilities: Theoretical Perspectives and Empirical Operationalization," in ICIS '99: Proceedings of the 20th international conference on Information Systems. / ICIS 1999 Proceedings. Paper 35., 1999, pp. 378-385.

[20] K. M. Eisenhardt and J. A. Martin, "Dynamic Capabilities: What Are They?," Strateg. Manag. J., vol. 21, no. 10-11, pp. 1105-1121, Oct. 2000.

[21] S. G. Winter, "Understanding dynamic capabilities," Strateg. Manag. J., vol. 24, no. 10, pp. 991-995, Oct. 2003.

[22] I. Barreto, "Dynamic Capabilities: A Review of Past Research and an Agenda for the Future," J. Manage., vol. 36, no. 1, pp. 256-280, Dec. 2009.

[23] P. A. Pavlou and O. A. El Sawy, "Understanding the Elusive Black Box of Dynamic Capabilities," Decis. Sci., vol. 42, no. 1, pp. 239-273, Feb. 2011.

[24] M. Zhang, S. Sarker, and S. Sarker, "Drivers and export performance impacts of IT capability in 'born-global' firms: a cross-national study," Inf. Syst. J., vol. 23, no. 5, pp. 419443, Sep. 2013.

[25] DAMA, The DAMA Guide to The Data Management Body of Knowledge (DAMA-DMBOK Guide), Fist Editi. Bradley Beach, New Jersey: Technics Publications, 2009.

[26] H. Chen, R. H. L. Chiang, and V. C. Storey, "Business Intelligence and Analytics: From Big Data to Big Impact," MIS Q., vol. 36, no. 4, pp. 1165-1188, 2012.

[27] H. Österle and B. Otto, "Consortium Research," Bus. Inf. Syst. Eng., vol. 2, no. 5, pp. 283-293, Aug. 2010.

[28] C. Sonnenberg and J. vom Brocke, "Reconsidering the BuildEvaluate Pattern in Design Science Research," in Design Science Research in Information Systems. Advances in Theory and Practice. Lecture Notes in Computer Science (Vol. 7286, pp. 381-397). Proceedings of the 7th DESRIST Conference, 2012, pp. 381-397.

[29] P. Timmers, "Business Models for Electronic Markets," Electron. Mark., vol. 8, no. 3, pp. 3-8, 1998.

[30] M. Iansiti and K. R. Lakhani, "Digital ubiquity: How connections, sensors, and data are revolutionizing business," Harv. Bus. Rev., vol. 92, no. 11, pp. 90-99, 2014.

[31] J. Lee and N. Berente, "Digital Innovation and the Division of Innovative Labor: Digital Controls in the Automotive Industry," Organ. Sci., vol. 23, no. 5, pp. 1428-1447, 2012. 
[32] Y. Lu and K. R. Ramamurthy, "Understanding the link between information capability and organizational agility: an empirical examination," MIS Q., vol. 35, no. 4, pp. 931-954, 2011.

[33] G. C. O'Connor, "Major Innovation as a Dynamic Capability: A Systems Approach," J. Prod. Innov. Manag., vol. 25 , no. 4 , pp. 313-330, 2008.

[34] P. A. Pavlou and O. A. El Sawy, "From IT Leveraging Competence to Competitive Advantage in Turbulent Environments: The Case of New Product Development," Inf. Syst. Res., vol. 17, no. 3, pp. 198-227, 2006.

[35] C. Holsapple, A. Lee-Post, and R. Pakath, "A unified foundation for business analytics," Decis. Support Syst., vol. 64, no. August, pp. 130-141, 2014.

[36] B. K. Chae and D. L. Olson, "Business Analytics for Supply Chain: a Dynamic-Capabilities Framework," Int. J. Inf. Technol. Decis. Mak., vol. 12, no. 1, pp. 9-26, Jan. 2013.

[37] B. Ghosh and J. E. Scott, "Antecedents and Catalysts for Developing a Healthcare Analytic Capability," Commun. Assoc. Inf. Syst., vol. 29, no. November, Article 22, pp. 395410, 2011.

[38] J. R. Galbraith, "Organization Design Challenges Resulting From Big Data," J. Organ. Des., vol. 3, no. 1, pp. 2-13, 2014.

[39] E. W. T. Ngai, D. C. K. Chau, and T. L. A. Chan, "Information technology, operational, and management competencies for supply chain agility: Findings from case studies," J. Strateg. Inf. Syst., vol. 20, no. 3, pp. 232-249, 2011.

[40] H. Lasi, H.-G. Kemper, P. Fettke, T. Feld, and M. Hoffmann, "Industry 4.0," Bus. Inf. Syst. Eng., vol. Catchword, 2014.

[41] E. Overby, "Process Virtualization Theory and the Impact of Information Technology," Organ. Sci., vol. 19, no. 2, pp. 277-291, Apr. 2008.
[42] A. Barua, P. Konana, A. B. Whinston, and F. Yin, "An empirical investigation of net-enabled business value," MIS $Q$., vol. 28, no. 4, pp. 585-620, 2004.

[43] V. Sambamurthy, A. Bharadwaj, and V. Grover, "Shaping Agility through Digital Options: Reconceptualizing the Role of Information Technology in Contemporary Firms," MIS Q., vol. 27, no. 2, pp. 237-263, 2003.

[44] C. R. Allred, S. E. Fawcett, C. Wallin, and G. M. Magnan, "A Dynamic Collaboration Capability as a Source of Competitive Advantage,” Decis. Sci., vol. 42, no. 1, pp. 129$161,2011$.

[45] S. E. Fawcett, C. Wallin, C. Allred, and G. M. Magnan, "Information Technology as an Enabler of Supply Chain Collaboration: A Dynamic-Capabilities Perspective," $J$. Supply Chain Manag., vol. 47, no. 1, pp. 38-59, 2009.

[46] K.-W. Huang and A. Sundararajan, "Pricing Digital Goods: Discontinuous Costs and Shared Infrastructure," Inf. Syst. Res., vol. 22, no. 4, pp. 721-738, 2011.

[47] E. K. Clemons and N. Madhani, "Regulation of Digital Businesses with Natural Monopolies or Third-Party Payment Business Models: Antitrust Lessons from the Analysis of Google," J. Manag. Inf. Syst., vol. 27, no. 3, pp. 43-80, Jan. 2010.

[48] D. J. Teece, "A dynamic capabilities-based entrepreneurial theory of the multinational enterprise," J. Int. Bus. Stud., vol. 45, no. 1, pp. 8-37, 2014.

[49] V. Dhar, M. Jarke, and J. Laartz, "Big Data,” Bus. Inf. Syst. Eng., vol. August, pp. 10-12, 2014.

[50] T. H. Davenport, "Analytics 3.0 - In the new era, big data will power consumer products and services," Harvard Business Review, no. 5, pp. 64-72, 2013. 